\title{
Development of a less toxic dichloroacetate analogue by docking and descriptor analysis
}

\author{
Kannan Subramanian ${ }^{1}$, Anand S Ramaian ${ }^{2}$ \\ ${ }^{1}$ Department of Chemical and Process Engineering, University of Canterbury, Christchurch, New Zealand. ${ }^{2}$ Department of Biotechnology, Sri \\ Venkateswara College of Engineering, Pennalur, Sriperumbudur 602 105, India; Kannan Subramanian - Email: kansvce@gmail.com *Corresponding \\ author
}

Received January 31, 2010; revised May 10, 2010; accepted June 08, 2010; published July 06, 2010

\begin{abstract}
:
Dichloroacetate (DCA) is a synthetic compound that promotes the activity of pyruvate dehydrogenase (PDH) by inhibiting its repressor protein called pyruvate dehydrogenase kinase (PDHK). The activation of PDH leads to a reduction in ambient cellular lactate concentrations both in vitro and in vivo which contributes to the therapeutic use of DCA in the treatment of systemic lactic acidosis in humans. The therapeutic potential of DCA is now being explored in disorders that are accompanied by elevations of lactate concentration such as in hypoxic cancer cells. Yet conflicting evidence regarding its mutagenic potential has been a major setback in its clinical trials. Hence, docking and descriptor analysis of halogen substituted DCA analogues were performed to find out a drug candidate with less toxicity and better binding affinity than DCA. The Docking analysis was carried out using human PDHK isozyme 2, the physiological receptor for DCA. Bromo(iodo)acetate and Diiodoacetate were found out to be the plausible analogues of DCA from this study.
\end{abstract}

Keywords: PDH, PDHK, DCA, Docking and descriptor analysis.

Abbreviations: DCA = Dichloroacetate, $\mathrm{PDH}=$ Pyruvate dehydrogenase, PDHK = Pyruvate dehydrogenase kinase.

\section{Background:}

Cancer development and its confrontation to chemotherapy depend, at least in part, on suppression of apoptosis. Although mitochondria are recognized as regulators of apoptosis, their importance as targets for cancer therapy has not been adequately explored or clinically exploited. Studies suggest that mitochondrial dysfunction in cancer cells may result in a characteristic aerobic glycolysis phenotype [1]. This bioenergetic feature is a good marker of cancer but has not been therapeutically pursued, as it is thought to be a result and not a cause of cancer; that is, the cells rely mostly on glycolysis for energy production because of permanent mitochondrial damage, preventing oxidative phosphorylation. It is also proposed that because early carcinogenesis occurs in a hypoxic microenvironment, the transformed cells initially have to rely on glycolysis for energy production [2]. However, this metabolic adaptation also appears to offer a proliferative advantage, suppressing apoptosis. Lactate formation during anaerobic glycolysis contributes to the breakdown of the extracellular matrix, facilitate cell mobility and increase the metastatic potential [3]. Many glycolytic enzymes have been recognized to also regulate apoptosis, and several oncoproteins induce the expression of glycolytic enzymes [4]. The switching in the metabolism of glucose to end with glycolysis in the cytoplasm by converting pyruvate to lactate or continue with glucose oxidation in the mitochondria is controlled by a gate-keeping mitochondrial enzyme, pyruvate dehydrogenase (PDH) which in turn is regulated by phosphorylation by $\mathrm{PDH}$ kinase (PDHK) [5].

Human PDHK has 4 isoforms which exhibit tissue-specific expression; PDHK1 is found in heart, pancreatic islets, and skeletal muscles; PDHK2 is expressed in all tissues; PDHK3 is present in testes, kidney, and brain; and PDHK4 is profuse in heart, skeletal muscle, kidney, and pancreatic islets [6]. Preferential expression of PDHK might contribute to its cancer selectivity. In a study of lung cancer specimens, cancer cells had increased PDHK2 and decreased PDH expression (compatible with a glycolytic phenotype) compared to neighboring non-malignant cells [7]. Selective inactivation of PDHK isoforms by the specific inhibitor dichloroacetate has been shown to trigger apoptosis by promoting a mitochondrial potassiumion channel which inhibits tumor growth $[5,8]$.

Dichloroacetate is effective in the treatment congenital lactic acidosis (CLA). People with CLA have defective PDH enzymes and are thus unable to efficiently produce energy. In one study, patients with CLA were treated with $25-50 \mathrm{mg}$ of dichloroacetate per $1 \mathrm{~kg}$ of body weight. No major complications were observed in the participants [9]. However other side effects were observed somewhat frequently. These side effects varied in their presentation and severity, but all involved the central nervous system. Reversible neuropathy, or altered sensory or motor neuron function was the most common symptom observed. One study found that $50 \%$ of patients treated with DCA developed this neuropathy causing the hindrance in pursuing further studies on using DCA for cancer therapy [10].

Thus in order to find a less toxic analogue of DCA a series of halogen substitutions were tried and their binding energies, toxicity, $\mathrm{C} \log \mathrm{P}, \mathrm{mi}$ $\log$, Drug score etc., were analyzed to sort out the better performing DCA analogues capable of inhibiting PDK. 
<smiles>O=C(O)C(Cl)Cl</smiles><smiles>O=C(O)C(I)I</smiles><smiles>O=C(O)C(F)F</smiles><smiles>O=C(O)C(Br)Br</smiles>

Di chloro acetatic acid Di iodo acetic acid Di fluoro acetic acid Di bromo acetic acid<smiles>O=C(O)C(Cl)Br</smiles>

btomo(chloro) acetic acid<smiles>O=C(O)C(F)Br</smiles>

bromo(fluoro) acetic acid<smiles>O=C(O)C(F)Cl</smiles>

chloro(fluoro) acetic acid<smiles>O=C(O)C(F)I</smiles>

fluoro(iodo) acetic acid<smiles>O=C(O)C(Cl)I</smiles>

chloro(iodo) acetic acid<smiles>O=C(O)C(Br)I</smiles>

bromo(iodo) acetic acid

Figure 1: Two dimensional structures of DCA and its halogen substituted analogues.

\section{Methodology:}

\section{Receptor and ligands}

The three dimensional crystal structure of pyrvuate dehydrogenase kinase 2 (PDB ID: 2BTZ) [11] was used as the receptor throughout the work and the two dimensional structures of the ligands were drawn using ACD chemsketch software [12]. The halogen substitutions using fluorine, iodine, bromine atoms were done on the DCA molecule with the following combinations DIA - Diiodoacetate, DFA - Difluoroacetate, DBrA Dibromoacetate, CIA -Chloro(iodo)acetate, CFA - Chloro(fluoro)acetate, BrCA - Bromo(chloro)acetate, BrIA - Bromo(iodo)acetate, FIA Fluoro(iodo)acetate and BrFA - Bromo(fluoro)acetate. The three dimensional structures of the ligands were obtained using the Dundee PRODRG tool [13].

\section{Docking and descriptor analysis:}

The docking scores of the prepared ligands with PDHK2 receptor were determined using Argus lab software and Autodock Vina [14, 15]. The molecular descriptors such as $\mathrm{C} \log \mathrm{P}$, mi $\log \mathrm{P}$, solubility, drug likeliness, Total Polar Surface Area (TPSA), molecular weight, volume, drug score, G-protein coupled receptors (GPCR) ligands, kinase inhibitor, ion channel modulator and nuclear receptor were obtained using Molinspiration [16] and OSIRIS Property explorer [17].

\section{Toxicity prediction:}

The toxicity analysis such as Ames test, mutagenicity, tumorogenic, irritant, reproductive effective, mouse LD50 and oral bioavailabilty were obtained using ADME-TOX BOX of Pharma Algorithms [18].

\section{Results and Discussion:}

Docking analysis

The Docking scores (Table 1 see supplementary material) were obtained from the analogues (Figure 1) with PDK2 as the receptor. The docking scores were the highest for DBrA with $-7.47 \mathrm{Kcal} / \mathrm{mol}$ followed by BrIA $7.36 \mathrm{Kcal} / \mathrm{mol}$, CIA $-7.32 \mathrm{Kcal} / \mathrm{mol}$, DIA with $-7.27 \mathrm{Kcal} / \mathrm{mol}$, DCA with $7.19 \mathrm{Kcal} / \mathrm{mol}$, BrCA with $-7.17 \mathrm{Kcal} / \mathrm{mol}$, DIA with $-7.27 \mathrm{Kcal} / \mathrm{mol}$, BrFA \& CFA with $-6.33 \mathrm{Kcal} / \mathrm{mol}$, FIA with $-6.62 \mathrm{Kcal} / \mathrm{mol}$ and DFA with $-5.88 \mathrm{Kcal} / \mathrm{mol}$.

\section{Descriptor analysis:}

The descriptor analyses for the halogen substituted analogues of DCA are listed in Table 1 (see supplementary material). The $\mathrm{C} \log \mathrm{P}$ which measures the hydrophilicity of the molecule, favouring its entry through the lipid bilayer, indicated DFA with a low value of -0.44 followed by CFA with a score of 0.13 . The solubility prediction showed DBrA with a high score of -1.44 . Drug likeness was low for DIA $(-1.97)$ and high for
BrFA (16.6). The drug score indicated DIA with a high value of 0.53 which is significantly higher than that of DCA with a value of 0.06 . The score for kinase inhibition was high for BrFA (-4.15) and least for DCA (5.18). The score for Nuclear receptor ligand was high for CFA (-3.4) and least for DCA (-4.52). The mi logP was highest for DIA (1.554) followed by BrIA (1.28). The TPSA was found to be a constant for all the analogues with a value of 37.299. The GPCR ligand value was highest for BrFA (3.82 ) and low for DCA (-4.85). Finally the ion channel modulator score was high for CFA (-2.18) and low for DCA (-4.5). It was observed from the data that certain desirable parameters such as $\mathrm{C} \log \mathrm{P}$, mi $\log \mathrm{P}$ and drug score were potent for advocating DIA and BrIA as effective analogues for DCA.

\section{Toxicity prediction:}

The Toxicity characteristics of the DCA analogues are listed in Table 1 (see supplementary material). The in silico studies on mutagenicity, tumorogenic, irritant and reproductive effective characteristics of DIA, DFA, BrIA, FIA and BrFA showed that they were in the safer levels. The Ames test values indicated DFA with a low value of 0.208 and BrIA with a high value of 0.517 . The LD50 values in the intraperitonial, oral, intravenous and subcutaneous as 710, 1400, 260 and $900 \mathrm{mg} / \mathrm{kg}$ respectively for DCA followed by 410, 1100, 310 and $650 \mathrm{mg} / \mathrm{kg}$ respectively for BrIA. It is interesting to note that in both the low toxic analogues, DIA and BrIA, iodine is a constituent whose importance is required to make this discussion complete.

Iodide is comparatively less toxic since nature has provided us with iodine metabolizing ability through thyroid gland. Studies have found an epidemiologic correlation between iodine deficiency, iodine-deficient goitre and gastric cancer [19]; a decrease of the incidence of death rate from stomach cancer after implementation of the effective iodineprophylaxis was reported with the proposed mechanism of action wherein the iodide ion functions in gastric mucosa as an antioxidant reducing species that can detoxify poisonous reactive oxygen species, such as hydrogen peroxide [20]. Further iodide moiety is more hydrophobic, which along with the overall small structure, compared to other anticancer drugs, makes the analogues an effective candidate to cross the blood brain barrier.

\section{Conclusion:}

The docking and toxicity analyses of DCA and its halogen substituted analogues showed that DIA and BrIA are effective in meeting the objectives of this study, namely low toxicity and high binding nature. Thus these analogues may be considered for further wet lab evaluation using in vitro and in vivo studies to develop an effective anti cancer drug. 
References:

[1] O Warburg, Science (1956) 123: 309 [PMID 13298683]

[2] RA Gatenby \& RJ Gillies Nat Rev Cancer (2004) 4: 891 [PMID: 15516961]

[3] DR Plas \& CB Thompson Trends Endocrinol Metab (2002) 13: 75 [PMID:11854022]

[4] JW Kim \& CV Dang, Trends Biochem Sci (2005) 30: 142 [PMID:15752986]

[5] S Bonnet et al, Cancer Cell (2007) 11: 37 [PMID:17222789]

[6] TR Knoechel et al, Biochemistry (2006) 45: 402 [PMID:16401071]

[7] MI Koukourakis et al, Neoplasia (2005) 7: 1 [PMID: 15736311]

[8] RA Cairns et al. Proc Natl. Acad. Sci. USA (2007) 104: 9445 [PMID: 17517659]

[9] PW Stacpoole et al. Archives of Disease in Childhood (1997) 77: 535 [PMID: 9496194]
[10] P Kaufmann et al. Neurology (2006) 66: 324 [PMID: 16476929]

[11] www.rcsb.org

[12] http://www.acdlabs.com

[13] AW Schuettelkopf \& DMF van Aalten Acta Crystallographica (2004) 60: 1355 [PMID:15272157]

[14] http://www.ArgusLab.com

[15] O Trott \& AJ Olson Journal of Computational Chemistry (2010) 31: 455 [PMID:19499576]

[16] http://www.molinspiration.com/

[17] http://www.organic-chemistry.org/prog/peo/

[18] http://pharma-algorithms.com/webboxes/

[19] R Behrouzian \& N Aghdami East Mediterr Health J (2004) 10: 921 [PMID:16335780]

[20] F Golkowski et al. Eur J Nutr (2007) 46: 251 [PMID:17497074]

Edited by $P$. Kangueane

Citation: Subramanian et al, Bioinformation 5(2): 73-76 (2010) License statement: This is an open-access article, which permits unrestricted use, distribution, and reproduction in any medium, for noncommercial purposes, provided the original author and source are credited. 


\section{Supplementry material:}

Table 1: Docking, molecular descriptor values \& toxicity scores of DCA and its analogues. ( $\mathrm{R}$ - Properties with high risks of undesired effects, O - Properties with moderate risk of undesired effects, G -Properties with drug-conform behaviour)

\begin{tabular}{|c|c|c|c|c|c|c|c|c|c|c|}
\hline Parameters/ Names & DCA & DIA & DFA & DBrA & CIA & CFA & BrCA & BrIA & FIA & BrFA \\
\hline $\begin{array}{l}\text { Dock score using } \\
\text { Auto dock vina } \\
\text { (Kcal/mol) }\end{array}$ & -4.1 & -4.1 & -4.2 & -4.2 & -4.2 & -4.1 & -4.2 & -4.3 & -4.2 & -4.1 \\
\hline $\begin{array}{l}\text { Docking score using } \\
\text { Argus lab(Kcal/mol) }\end{array}$ & -7.19 & -7.27 & -5.88 & -7.47 & -7.32 & -6.33 & -7.17 & -7.36 & -6.62 & -6.63 \\
\hline Mutagenicity & $\mathrm{R}$ & G & G & G & $\mathrm{R}$ & $\mathrm{R}$ & $\mathrm{R}$ & G & G & G \\
\hline Tumorogenic & $\mathrm{R}$ & G & G & $\mathrm{R}$ & $\mathrm{O}$ & $\mathrm{O}$ & $\mathrm{R}$ & G & G & G \\
\hline Irritant & $\mathrm{R}$ & G & G & G & $\mathrm{O}$ & $\mathrm{O}$ & $\mathrm{O}$ & G & G & G \\
\hline $\begin{array}{l}\text { Reproductive } \\
\text { effective }\end{array}$ & $\mathrm{R}$ & G & G & $\mathrm{R}$ & G & G & G & G & G & G \\
\hline$C \log P$ & 0.49 & 1.27 & -0.44 & 0.59 & 0.88 & 0.13 & 0.54 & 0.93 & 0.52 & 0.18 \\
\hline Solubility & -1.16 & -0.6 & -0.93 & -1.44 & -0.88 & -1.07 & -1.3 & -1.02 & -0.8 & -1.22 \\
\hline Molecular Weight & 128 & 312 & 96 & 216 & 220 & 112 & 172 & 264 & 204 & 156 \\
\hline Drug likeness & -3.82 & -1.97 & -9.89 & -10.5 & -3.6 & -10.8 & -12.9 & -9.4 & -8.87 & -16.6 \\
\hline Drug score & 0.06 & 0.53 & 0.49 & 0.17 & 0.19 & 0.19 & 0.14 & 0.48 & 0.49 & 0.49 \\
\hline Ames Test & 0.463 & $\begin{array}{c}0.48 \\
9\end{array}$ & $\begin{array}{c}0.20 \\
8\end{array}$ & 0.576 & $\begin{array}{c}0.46 \\
4\end{array}$ & $\begin{array}{c}0.32 \\
8\end{array}$ & 0.514 & 0.517 & 0.32 & 0.37 \\
\hline $\begin{array}{l}\text { Intraperitoneal } \\
\text { (mg/kg) }\end{array}$ & 710 & 330 & 179 & 160 & 210 & 340 & 400 & 410 & 120 & 83 \\
\hline Oral (mg/kg) & 1400 & 1100 & 430 & 620 & 730 & 660 & 920 & 1100 & 470 & 350 \\
\hline Intravenous (mg/kg) & 260 & 450 & 110 & 120 & 210 & 160 & 170 & 310 & 180 & 87 \\
\hline $\begin{array}{l}\text { Subcutaneous } \\
\text { (mg/kg) }\end{array}$ & 900 & 560 & 160 & 290 & 370 & 390 & 580 & 650 & 180 & 130 \\
\hline Kinase inhibitor & -5.18 & -4.42 & -4.84 & -4.52 & -4.56 & -4.21 & -4.26 & -4.49 & -4.44 & -4.15 \\
\hline $\begin{array}{l}\text { Nuclear receptor } \\
\text { ligand }\end{array}$ & -4.52 & -3.83 & -4.12 & -4.14 & -3.87 & -3.4 & -4.18 & -4.48 & -3.69 & -4.01 \\
\hline mi $\log P$ & 0.744 & $\begin{array}{c}1.55 \\
4\end{array}$ & $\begin{array}{c}0.12 \\
8\end{array}$ & 1.006 & $\begin{array}{c}1.14 \\
9\end{array}$ & $\begin{array}{c}0.43 \\
6\end{array}$ & 0.875 & 1.28 & 0.841 & 0.567 \\
\hline TPSA & 37.299 & $\begin{array}{c}37.2 \\
99\end{array}$ & $\begin{array}{c}37.2 \\
99\end{array}$ & 37.299 & $\begin{array}{c}37.2 \\
99\end{array}$ & $\begin{array}{c}37.2 \\
99\end{array}$ & 37.299 & 37.299 & 37.299 & 37.299 \\
\hline Volume & 83.536 & $\begin{array}{c}104 . \\
44\end{array}$ & $\begin{array}{c}66.3 \\
27\end{array}$ & 92.235 & $\begin{array}{c}93.9 \\
9\end{array}$ & $\begin{array}{c}74.9 \\
31\end{array}$ & 87.885 & 98.339 & 85.385 & 79.281 \\
\hline GPCR ligand & -4.85 & -4.09 & -4.42 & -4.26 & -4.26 & -3.83 & -4.04 & -4.26 & -4.05 & -3.82 \\
\hline $\begin{array}{l}\text { Ion channel } \\
\text { modulator }\end{array}$ & -4.5 & -3.89 & -4.11 & -4.39 & -3.98 & -2.18 & -4.09 & -4.46 & -3.81 & -3.92 \\
\hline
\end{tabular}

